\title{
MEDIAÇÃO PEDAGÓGICA NA EDUCAÇÃO A DISTÂNCIA: A IMPORTÂNCIA DO FEEDBACK
}

Ana Mayra Samuel da Silva, Ana Virginia Isiano Lima, Janaina Pereira Duarte Bezerra

Universidade Estadual Paulista - UNESP, Programa de Pós-Graduação em Educação, Presidente Prudente, SP. E-mail: ana.mayra.ss@gmail.com.

\section{RESUMO}

O artigo científico tem como objetivo apresentar uma experiência de tutoria e sua relação com a mediação pedagógica e o feedback, em um curso oferecido na modalidade a distância. Adotamos a abordagem metodológica de uma pesquisa qualitativa. Para a coleta de dados utilizamos estudo bibliográfico e diário de campo da primeira autora deste trabalho, que atuou como tutora colaboradora do curso intitulado "Mediação Pedagógica: Tutoria em EaD (Formação de Tutores: Mediação e Feedback)" desenvolvido e oferecido pelo Núcleo de Educação a Distância (NEaD) da Universidade Estadual Paulista "Júlio de Mesquita Filho" (UNESP). Assim, neste artigo abordaremos a importância do Feedback na Mediação Pedagógica e na relação entre professor tutor e estudante cursista. Concluímos que os feedbacks formativos são extremamente importantes para uma boa mediação pedagógica entre tutor e cursista, visto que os mesmos auxiliam os estudantes a ter consciência de suas dificuldades e potencialidades.

Palavras-chave: Educação a Distância, Mediação Pedagógica, Tutor Online, Feedback.

\section{PEDAGOGICAL MEDIATION IN DISTANCE EDUCATION: THE IMPORTANCE OF THE FEEDBACK}

\begin{abstract}
The aim of the scientific article is to present a mentoring experience and its relation with pedagogical mediation and feedback, in a course offered in the distance modality. We adopted the methodological approach of a qualitative research. In order to collect data, we used a bibliographic study and field diary, who served as a collaborative tutor for the course entitled "Pedagogical Mediation: Tutoring in EaD (Training of Tutors: Mediation and Feedback)" developed And offered by the Nucleus of Distance Education (NEAD) of the Paulista State University "Júlio de Mesquita Filho" (UNESP). Thus, in this article we will discuss the importance of Feedback in Pedagogical Medication and in the relationship between tutor and student. We conclude that the formative feedbacks are extremely important for a good pedagogical mediation between tutor and student, since they help the students to be aware of their difficulties and potentialities.
\end{abstract}

Keywords: Distance Education, Pedagogical Mediation, Online Tutor, Feedback 


\section{INTRODUÇÃO}

A Educação à Distância (EaD) em nosso país passou a ser reconhecida a partir da Lei de Diretrizes e Bases para a Educação Nacional (LDBEN), de 1996, que, em seu artigo 80 estabelece que, fica a cargo do Poder Público incentivar o desenvolvimento "o Poder Público incentivará o desenvolvimento e a veiculação de programas de ensino a distância, em todos os níveis e modalidades de ensino, e de educação continuada". O Decreto 5622, de 2005, caracteriza, em seu artigo 10, a EaD como uma modalidade de ensino em que a mediação pedagógica entre professores tutores e estudantes acontece por meio da utilização de Tecnologias Digitais de Informação e Comunicação (TDIC), em tempos e lugares diversos.

A EaD, a partir de diversas bases legais, passou a ser reconhecida como um instrumento que favorece mudanças no modelo educacional tradicional, capaz de influenciar a política nacional de educação. Contudo, deve ser realizada de maneira integra e responsável pois deve oferecer um processo pedagógico adequado às necessidades dos estudantes e corresponder a um ensino socialmente significativo e contextualizado. Assim, percebemos o quão importante é para os estudantes, professores, tutores, gestores e atuantes da modalidade EaD a mediação pedagógica, que tem por intuito auxiliar o cursista a desenvolver e construir o seu próprio conhecimento a partir de suas vivências e interações no ambiente virtual de aprendizagem.

No entanto, na modalidade EaD o papel do professor ou tutor precisa ser repensando, uma vez que não podemos mais enxerga-lo como um mero repassador de informações que organiza, dinamiza e orienta a construção do conhecimento para o estudante. Nesta modalidade o tutor se torna responsável por mediar e potencializar o saber do estudante. Para tanto, a comunicação entre tutor e estudante se torna mais importante do que a transmissão de informações, pois é por meio dela que o processo de construção de conhecimentos acontecerá.

Conforme Costa (2013, p. 106),

Entende-se que a função do tutor assume várias significações de acordo com o tempo histórico no qual está inserido bem como depende da estrutura organizativa de cada instituição. Seu significado etimológico ganha novas interpretações e exige desse profissional o comprometimento e o conhecimento da EAD. Assim, não basta apenas ter a vontade de ser um tutor, é preciso estar envolvido em todo o processo que o constitui.

Segundo o Ministério da Educação (BRASIL, 2007) os tutores desempenham papel de fundamental importância no processo educacional de cursos/disciplinas oferecidas na modalidade EaD.

A tutoria a distância atua a partir da instituição, mediando o processo pedagógico junto a estudantes geograficamente distantes, e referenciado aos polos descentralizados de apoio presencial. Sua principal atribuição deste profissional é o esclarecimento de dúvidas através fóruns de discussão pela Internet, pelo telefone, participação em videoconferências, entre outros, de acordo com o projeto pedagógico (BRASIL, 2007, p. 21).

Sendo assim, o tutor trabalha com os estudantes por meio das tecnologias, contribuindo com o crescimento de sua aprendizagem por meio da medicação pedagógica permeada por mensagens, e-mails, e orientações por meio do Ambiente Virtual de Aprendizagem (AVA), e outros meios que auxiliam ao estudante a estar junto virtualmente com o seu professor tutor.

O motivo de se destacar o diálogo entre os tutores decorre do fato de que nesse ambiente é possível extrapolar a mera indicação de uma leitura do livro texto, acrescentando informações complementares que enriquecem a abordagem dos conteúdos propostos na disciplina. Por tudo isso, conclui- 
se que está havendo uma mediação na comunicação professor-aluno em relação aos conteúdos trabalhados. (COSTA, 2013, p. 114).

Segundo Sá (1998, p. 46) "exige-se mais do tutor de que de cem professores convencionais". Pois, este profissional, além de ter uma boa formação acadêmica, precisa desenvolver algumas habilidades pessoais como a comunicação, organização, disciplina e responsabilidade.

A formação acadêmica do tutor deve auxiliá-lo a desenvolver a capacidade intelectual, didática, domínio dos conteúdos próprios à modalidade $\mathrm{EaD}$, bem como técnicas metodológicas. Além disso, imerso em um curso ou uma disciplina nesta modalidade é necessário que ele conheça com profundidade os assuntos relacionados e temas transversais, uma vez que assume o papel de mediador do conhecimento do estudante. Em sua formação, este profissional precisa compreender algumas habilidades e ações como o ato de planejar, acompanhar e avaliar as atividades, sempre motivando o estudante para que o mesmo tenha êxito em seu processo de construção do conhecimento.

Em relação à formação pessoal se faz necessário que este profissional seja capaz de trabalhar com um grupo heterogêneo de estudantes. Para tanto o tutor precisa desenvolver sua empatia pelos envolvidos neste processo, mediar questões, liderar o grupo com práticas inovadoras, e ser capaz de ouvir e compreender os estudantes.

Para Arnaldo Niskier (1999), para ser um tutor se faz necessário reunir as qualidades de um planejador, comunicador, pedagogo e técnico em Informática. Pois, suas atribuições estão relacionadas à sua participação na produção e seleção dos materiais, avaliação permanente que tenha por objetivo aperfeiçoar a modalidade EaD.

Em relação à mediação pedagógica na EaD, o papel do tutor é fundamental, pois este irá tentar prever as possíveis dificuldades dos estudantes, buscando sempre antecipar algumas soluções de maneira clara e rápida.

A função do tutor online para a mediação pedagógica é orientar, dirigir, supervisionar e avaliar o processo de ensino e de aprendizagem do estudante cursista. Desta forma, o objetivo é apresentar uma experiência de tutoria e sua relação com a mediação pedagógica e o feedback, em um curso oferecido na modalidade a distância.

\section{METODOLOGIA}

A abordagem escolhida para o desenvolvimento é a qualitativa. De acordo com Richardson (2012, p. 80),

os estudos que empregam uma metodologia qualitativa podem descrever a complexidade de determinado problema, analisar a interação de certas variáveis, compreender e classificar processos dinâmicos vividos por grupos sociais, contribuir no processo de mudança de determinado grupo e possibilitar, em maior nível de profundidade, o entendimento das particularidades do comportamento dos indivíduos.

Este autor justifica que essa abordagem permite aos pesquisadores compreender a natureza de fenômenos sociais e, assim, buscar soluções teóricas e práticas para a situação vivenciada. Assim, a partir da abordagem qualitativa, esse trabalho prevê apresentar a importância da relação entre o tutor e o cursista e mediação pedagógica por meio do feedback em cursos oferecidos na modalidade EaD.

Assim, empregamos a técnica da observação participante. De acordo com Lakatos e Marconi (2010, p. 176), na observação participante "o observador sabe o que procura e o que carece de importância em determinada situação; deve ser objetivo, reconhecer possíveis erros e 
eliminar sua influência sobre o que vê ou recolhe". Assim, a autora deste trabalho também atuou como tutora do curso de formação de tutores, analisando as atividades relacionadas ao feedback que os cursistas deveriam produzir.

Para divulgação dos dados submetemos um projeto ao Comitê de Ética e Pesquisa (CEP), sendo o protocolo de aprovação: 10206912.2.0000.5402.

\section{RESULTADOS}

Neste tópico será apresentado a importância do Feedback na Medicação Pedagógica, bem como um relato da experiência da primeira autora, como tutora do Curso "Mediação Pedagógica: Tutoria em EaD (Formação de Tutores: Mediação e Feedback)" desenvolvido e oferecido pelo Núcleo de Educação a Distância (NEaD) da Universidade Estadual Paulista "Júlio de Mesquita Filho" (UNESP).

De acordo com Mory (2004) o feedback pode ser compreendido como um procedimento ou comunicação realizada pelo professor para informar o estudante sobre o seu desenvolvimento educacional. Além disso, permite que o estudante acompanhe seu desempenho acadêmico, permitindo que o mesmo modele suas ações a partir de suas percepções. Ainda conforme o autor, o feedback continua sendo fundamental no processo de ensino e de aprendizagem, independente do nível e da modalidade.

Sem o feedback, os estudantes não podem ter consciência dos conteúdos que necessitam de mais estudos, não sabem se estão seguindo a linha de raciocínio correta, se podem manter ou repetir as mesmas ações.

Shute (2008, p.153) defende o feedback formativo, ou seja, "é a revisão como informação comunicada para o aprendiz com a intenção de modificar seu comportamento ou seu modo de pensar objetivando uma melhoria no aprendizado". O feedback formativo tem por intuito modificar significativamente os resultados acadêmicos do estudante, para tanto, o professor tutor precisa obedecer à alguns fatores, bem como: tempo, informações relevantes devidamente pontuadas, coerência, linguagem, entre outros. Conforme Perrenoud (apud Hadji, 2001, p.20), é "formativa toda avaliação que auxilia o aluno a aprender e a se desenvolver, ou seja, que colabora para a regulação das aprendizagens e do desenvolvimento no sentido de um projeto educativo".

Assim, a primeira autora deste trabalho, foi convidada em 2015 para atuar como tutora colaboradora do Curso "Mediação Pedagógica: Tutoria em EaD (Formação de Tutores: Mediação e Feedback)" desenvolvido e oferecido pelo Núcleo de Educação a Distância (NEaD) da Universidade Estadual Paulista "Júlio de Mesquita Filho" (UNESP). Esta foi sua primeira experiência com a Educação a Distância (EaD). Haviam trinta cursistas, sendo dez de responsabilidade da autora deste trabalho.

O Curso teve por objetivo explorar as principais ferramentas do Ambiente Virtual de Aprendizagem (AVA) Moodle e estudar seu potencial para a comunicação, interação, interatividade e aprendizagem on-line, além de ampliar o repertório técnico destas ferramentas, bem como identificar características importantes que o tutor on-line deve empreender para o ensino a distância e analisar os mecanismos de mediação pedagógica e feedback em Educação a Distância (EaD). O curso teve duração de 180 horas divididas em 10 horas de estudos semanais, compreendendo 5 módulos. As atividades realizadas pelos estudantes foram: assistir vídeoaula, participar de debates e discussões nos fóruns, realizar leitura crítica de textos, realizar exercícios, análise de situações fictícias contextualizadas, entre outros. Ainda, foram disponibilizados espaços no AVA para interação entre os participantes, como: chat, fóruns de apresentação e sala virtual.

De acordo com as descrições acima, referente ao Curso, se pode perceber que o mesmo priorizou atividades práticas que levassem aos cursistas refletir sobre sua futura atuação enquanto tutores. Afinal, um de seus objetivos foi apresentar elementos teóricos e práticos para a atuação de profissionais em cursos de Educação a Distância, proporcionando conhecimentos que 
contribuam para a mediação pedagógica e desenvolvimento da comunicação, interação e interatividade em ambientes virtuais de aprendizagem.

Sendo assim, umas das atividades deste curso consistiu em um Exercício de Feedback. Para tanto, foi apresentado aos cursistas uma situação-problema em que o estudante cometeu plágio em sua resposta, e, o tutor por sua vez deveria elaborar um feedback seguindo alguns critérios, a saber: utilizar recursos da Web 2.0, abordar a questão do plágio de forma ética, sem se esquecer se ressaltar os aspectos positivos da resposta do estudante. Apresentaremos a seguir alguns exemplos das atividades realizadas pelos cursistas e os feedbacks formativos que foram elaborados pelos menos e pela tutora, demonstrando assim a importância da mediação pedagógica na EaD.

A fim de atender as exigências da atividade, o cursista B. elaborou um vídeo explicativo sobre o plágio, realizando sua publicação na rede social Youtube e encaminhamento por e-mail como fundamental para todos os estudantes. Além disso, elaborou um feedback formativo e individual para o estudante da situação-problema, respondendo ao seu questionamento, ressaltando a importância da pesquisa efetuada para realização da atividade e apresentando questões específicas sobre o plágio de maneira gentil e educada.

O feedback enviado pela tutora para o cursista B. foi elaborado por meio de um recurso da Web 2.0 denominado $\mathrm{Voki}^{1}$. Este recurso permite ao usuário criar um Avatar animado, que traduz para a língua oral o feedback escrito. Neste a tutora buscou ressaltar a importância desta atividade para sua formação enquanto futuro professor on-line, bem como outras questões que poderiam ter sido levantadas para melhor elaboração da atividade supracitada.

O cursista A. elaborou um Avatar animado por meio do Voki, evidenciando a participação do estudante e interesse em realizar as atividades em tempo hábil para correções e aperfeiçoamentos do trabalho, apresentando assim a questão do plágio de forma educada e interativa, propondo melhorias. Além disso, o cursista enviou para o estudante o mesmo texto escrito pensando na conexão da internet e interação com os recursos da Web 2.0.

O feedback enviado pela tutora para o cursista A. foi elaborado por meio de um texto explicativo publicado em um Blog sobre EaD e as especificidades do feedback. Assim como no feedback anterior, a tutora buscou ressaltar a importância do exercício de feedback para a formação do professor tutor.

As atividades dos demais cursistas para este Exercício de Feedback foram variadas e diversificadas. Alguns realizaram vídeos e fizeram uso do Youtube, Google Drive, Blogs Educativos, Artigos publicados em base de dados de programas de pós-graduação, Voki, Skype, entre outras redes de informações e comunicação.

\section{DISCUSSÃO}

Segundo Paiva (2003), o feedback, enquanto mediação pedagógica tem por objetivo avaliar o desempenho no processo de ensino e de aprendizagem do estudante cursista, e assim refletir sobre a interação entre professor e estudante, de forma a estimulá-la, sempre visando a construção de conhecimentos. De acordo com o exemplo acima, podemos verificar que o cursista compreendeu que o papel do tutor é o de oferecer subsídios para que a aprendizagem do estudante cresça na medida em que ele se desenvolve no curso. Assim, o cursista optou por elaborar um vídeo formativo e um feedback individual para atender as necessidades específicas do estudante.

Vrasidas e Mclsaac (1999) afirmam que o feedback é um importante recurso para a mediação pedagógica na $\mathrm{EaD}$, pois influencia diretamente na qualidade e na intensidade da interação entres os agentes educacionais participantes deste processo de construção de saberes. Segundo pesquisas realizadas por estes autores, os estudantes valorizam os feedbacks

\footnotetext{
${ }^{1}$ O Feedback da tutora pode ser encontrado em: http://www.voki.com/pickup.php?scid=11681531\&height=267\&width=200
} 
individualizados, ou seja, com mensagens pautadas em experiências com as atividades realizadas, pois esta atitude do professor tutor auxilia a dinâmica de participação e desenvolvimento do processo de construção de conhecimentos, uma vez que se torna mais significativo.

Conforme percebemos com os exemplos supracitados acima, com os feedbacks formativos e individualizados os estudantes se sentem assistidos e motivados a prosseguir seus estudos, pois se sentem pertencentes ao curso/disciplina.

\section{CONCLUSÃO}

Considerando que na EaD existe uma situação-problema relacionada à distância, espaço e tempo distintos entre o estudante e o professor tutor, precisamos refletir um pouco mais sobre a maneira de ensinar e a forma como os indivíduos aprendem. Assim, podemos considerar que a mediação pedagógica na EaD deve estar presente nos cursos de formação de professores tutores, uma vez que estes são fundamentais para o processo de construção de conhecimentos e saberes em cursos/disciplinas oferecidos nesta modalidade.

Sendo assim, o foco deste artigo foi apresentar o feedback, mas especificadamente o formativo e individualizado, como instrumento significativo para a mediação pedagógica na EaD, uma vez que podemos, enquanto tutores, nos aproximar dos cursistas podendo assim contribuir com seu processo de ensino e de aprendizagem. Portanto, consideramos que, para a mediação pedagógica na EaD, o feedback individualizado e formativo é essencial, uma vez que permite ao estudante cursista obter elementos necessários para rever suas dificuldades e aprimorar suas potencialidades.

\section{REFERÊNCIAS}

BRASIL. Senado Federal. Lei de Diretrizes e Bases da Educação Nacional: no 9304/96. Brasília: 1996.

BRASIL. Ministério da Educação. Decreto Federal no. 5.622, de 20.12.2005. Regulamenta o art. 80 da Lei no. 9.394, de 20 de dezembro de 1996, que estabelece as diretrizes e bases da educação nacional. Brasília: 2005.

BRASIL. Ministério da Educação. Secretaria de Educação a Distância. Referenciais de qualidade para educação superior a distância. Brasília, DF: MEC, 2007.

COSTA, M. L. F. Educação a distância no Brasil. Maringá: Eduem, 2013.

HADJI, C. Avaliação desmistificada. Porto Alegre: Artmed, 2001.

LAKATOS, E. M.; MARCONI, M. A. Fundamentos de Metodologia Científica: técnicas de pesquisa. 7 ed. São Paulo: Atlas, 2010.

MORY, E. H. Feedback research review. In: JONASSEM, D. (Comp.). Handbook of research on educational communications and technology. Mahwah: Lawrence Erlbaum, 2004. p. 745-783.

NISKIER, A. Educação a Distância: A Tecnologia da Esperança. São Paulo, Loyola, 1999.

PAIVA, V. L. M. O. Feedback em Ambiente Virtual. In: LEFFA, V. (Org.) Interação na aprendizagem das línguas. Pelotas: EDUCAT, 2003. 
RICHARDSON, R. J. et al. Pesquisa social: métodos e técnicas. 3. ed. 14. reimpr. São Paulo: Atlas, 2012.

SÁ, I. M. A. Educação a Distância: Processo Contínuo de Inclusão Social. Fortaleza, C.E.C., 1998.

SHUTE, V. J. Focus on formative feedback. Review of Educational Research, Princeton, v. 1, n. 78, p. 153-189, 2008, https://doi.org/10.3102/0034654307313795.

VRASIDAS, C. e McISAAC, M.S. Factors Influencing Interaction in an Online Course. American Journal of Distance Education, 1999. http://dx.doi.org/10.1080/08923649909527033. 